\title{
COMMENTARY
}

\section{Rapid response systems: you won't know there is a problem until you measure it}

Ken M Hillman ${ }^{* 1,2,3}$

See related research by Oglesby et al., http://ccforum.com/content/15/4/R180

\begin{abstract}
The rapid response system concept is one of the first patient-centered and organizational-wide systems aimed at preventing deaths and serious adverse events. It has been strongly argued that we need a benchmark that reflects the care of a deteriorating patient across the organization using a 'score to door time'; that is, the time from the first vital sign abnormality to admission to the ICU. The study by Oglesby and colleagues highlights serious issues, especially delays, which could adversely impact on patient care, and the study proposes that we concentrate more on measuring patient care from a broad perspective.
\end{abstract}

Oglesby and colleagues' article uses the concept of a rapid response system (RRS) to identify delays in the definitive management of seriously ill patients [1]. The intuitive appeal of defining a deteriorating patient and responding rapidly in order to improve clinical outcomes is not difficult to understand [2]. Such systems have been reported to be associated with a significant reduction in deaths and cardiac arrests in pediatric hospitals [3], a reduction in adult hospital cardiac arrests [4] and a reduction in mortality in adult hospitals [5].

The development of a patient-centered system operating across the whole hospital has shed light on many issues related to the management of hospitalized patients. These issues include recognition that many patients, who are the subject of a RRS call, are naturally dying and should have been noted as do not attempt resuscitation (DNAR) at an earlier stage [6]; the recognition of the variable and poor nature of vital-sign recordings in hospitals [7-9]; and recognition of the need to empower

*Correspondence: k.hillman@unsw.edu.ai

3'ntensive Care, Liverpool Hospital, Locked Bag 7103, Liverpool BC, NSW 1871, Australia

Full list of author information is available at the end of the article bedside staff to call when the patient has predefined criteria [9]. Oglesby and colleagues' article sheds light on how difficult it is to implement efficient patient-centered systems.

Implementing this simple patient intervention within the complexity of acute hospitals can be a challenge. A RRS operates across the usual hospital silos and can expose weakness in the global care of patients, such as variability in the level of care for the seriously ill between different home teams, variability in resources necessary to recognize and respond rapidly, as well as access to intensive care beds.

Oglesby and colleagues' article describes something relatively unique - a benchmark that aims to evaluate whether a system operating across the whole hospital is effective. The 'score to door time' gives a good indication of how well the system, and all its components, are working. For example, measurement of the vital signs, triggering a response, initial management of the patient, and then the sometimes complex steps needed to secure admission to the ICU.

It was sobering to see the results of the study: including a surprisingly long time (median 0.47 hours) between recognition of the deteriorating patient and the response: this could not be described as rapid; and the protracted period before admission to the ICU (median 2.45 hours) [1]. One can possibly understand the complexities in arranging an admission to the ICU, but the term RRS implies that a potentially seriously ill patient needs to be seen as a matter of urgency, and yet it was around 45 minutes before patients were seen. Even more sobering was that the 'score to door time' was longer for more vulnerable patients who were older and who had a higher APACHE II score. The article by Oglesby and colleagues does not include what effect this had on patient outcome, but many other studies have demonstrated marked adverse patient outcomes as a result of delays in management [10-14].

The study's key point is related to the importance of outcome indicators that reflect the whole system, which, in turn, encourages all participants in the system to firstly see its overall failings and then to drill down on individual 
processes that could be improved. Other overall measurements of a systems' effectiveness include the rate of urgent calls, which correlates with a reduction in mortality and cardiac arrests [5], and the rate of potentially preventable deaths and cardiac arrests [15]. Only by measuring these outcomes can we understand the extent of the problems with patient care; and then identify the parts of the system that are failing and, finally, track the effectiveness of attempts to improve patient outcomes.

\section{Abbreviations}

RRS, rapid response system.

\section{Competing interests}

The author declares that he has no competing interests.

\section{Author details}

'Simpson Centre for Health Services Research, Australian Institute of Health Innovation, The University of New South Wales, Sydney 2052, Australia. ${ }^{2}$ Department of Intensive Care, The University of New South Wales, Sydney 2052, Australia. Intensive Care, Liverpool Hospital, Locked Bag 7103, Liverpool BC, NSW 1871, Australia.

Published: 28 October 2011

\section{References}

1. Oglesby KJ, Durham L, Welch J, Subbe CP: 'Score to Door Time', a benchmarking tool for rapid response systems: a pilot multi-centre service evaluation. Crit Care 2011, 15:R180.

2. Lee A, Bishop G, Hillman K, Daffurn K: The medical emergency team. Anaesth Intensive Care 1995, 23:183-186.

3. Chan PS, Khalid A, Longmore LS, Berg RA, Kosiborod M, Spertus JA: Hospitalwide code rates and mortality before and after implementation of a rapid response team. JAMA 2008, 300:2506-2513.

4. Chan PS, Jain R, Nallmothu BK, Berg RA, Sasson C: Rapid response teams. A systematic review of meta-analysis. Arch Intern Med 2010, 170:18-26.

5. Chen J, Bellomo R, Flabouris A, Hillman K, Finfer S; MERIT Study Investigators for the Simpson Centre; ANZICS Clinical Trials Group: The relationship between early emergency team calls and serious adverse events. Crit Care Med 2009, 37:148-153.

6. Chen J, Flabouris A, Bellomo R, Hillman K, Finfer S; MERIT Study Investigators for the Simpson Centre; ANZICS Clinical Trials Group: The medical emergency team system and not-for-resuscitation orders: results from the MERIT study. Resuscitation 2008, 79:391-397.

7. Fieselmann JF, Hendryx MS, Helms CM, Wakefield DS: Respiratory rate predicts cardiopulmonary arrest for internal medicine inpatients. J Gen Intern Med 1993, 8:354-360.

8. Cretikos MA, Bellomo R, Hillman K, Chen J, Finfer S, Flabouris A: Respiratory rate: the neglected vital sign. Med J Aust 2008, 188:657-659.

9. Hillman K, Chen J, Cretikos M, Bellomo R, Brown D, Doig G, Finfer S, Flabouris A; MERIT Study Investigators: Introduction of the medical emergency team (MET) system: a cluster-randomized controlled trial. Lancet 2005, 365:2091-2097.

10. Rivers EP, Nguyen HB, Huang DT, Donnino W: Critical care and emergency medicine. Curr Opin Crit Care 2002, 8:600-606

11. Sebat F, Musthafa AA, Johnson D, Kramer AA, Shoffner D, Eliason M, Henry K, Spurlock B: Effect of a rapid response system for patients in shock on time to treatment and mortality during 5 years. Crit Care Med 2007, 35:2568-2575.

12. Skrifvars MB, Nurmi J, Ikola K, Saarinen $K$, Castren M: Reduced survival following resuscitation in patients with documented clinically abnormal observations prior to in-hospital cardiac arrest. Resuscitation 2006, 70:215-222.

13. Calzavacca P, Licari E, Tee A, Egi M, Downey A, Quach J, Haase-Fielitz A, Haase $M$, Bellomo R: The impact of rapid response system on delayed emergency team activation patient characteristics and outcome - a follow-up study. Resuscitation 2010, 81:31-35.

14. Jones D, Opdam H, Egi M, Goldsmith D, Bates S, Gutteridge G, Kattula A, Bellomo R: Long-term effect of a medical emergency team on mortality in a teaching hospital. Resuscitation 2007, 74:235-241.

15. Hillman K, Alexandrou E, Flabouris M, Brown D, Murphy J, Daffurn K, Flabouris A, Parr M, Bishop G: Clinical outcome indicators in acute hospital medicine. Clin Intensive Care 2000, 11:89-94.

doi:10.1186/cc10477

Cite this article as: Hillman KM: Rapid response systems: you won't know there is a problem until you measure it. Critical Care 2011, 15:1001. 